\title{
Role of Parents, Community, and Health Care System in Child Health
}

\author{
Mishal Liaqat* \\ MS. Nursing Student, University of Lahore, Pakistan \\ Muhammad Hussain \\ Assistant Professor, University of Lahore, Pakistan \\ Muhammad Afzal \\ Assistant Professor, University of Lahore, Pakistan \\ Syed Amir Gillani \\ Professor, University of Lahore, Pakistan
}

\begin{abstract}
Pakistan is a developing country, and the status of children's health is less than satisfactory all over the region. This is evident by the high morbidity and mortality rate of under-five children. The shocking aspect is that the majority of causes are those that can be prevented and treated. Factors contributing to child health are parenting cultural values, physical environment, education, poverty, housing, and health care facilities. All these determinants emphasize that child health is encircled around three essential features of society parents, community, and health services. Focusing on just one will not bring an effective outcome until a collaborative approach is achieved. Here in this article model of child health proposed by the Better Start Child Health and Development Research Group at the University of Adelaide's School of Population is applied to address child health. Health gives as a rubric of "Five by Five" that is based on the concept that there are five basic domains of child health and each requires a collaborative approach of child, parents, community and health system.
\end{abstract}

Keywords: Child health, health services, Parents, Community

DOI: $10.7176 / \mathrm{JMPB} / 62-03$

Publication date: December $31^{\text {st }} 2019$

\section{Introduction}

It is said that the health of a nation can be best determined by the health of its children. A nation can be developed only if its children are healthy and develop to their full potential. According to the world health organization, child health is a state of complete physical, mental and social, intellectual and emotional wellbeing and not merely the absence of disease and infirmity. The status of children is compromised all over the world. Despite all progress and a great deal towards child health in the last two decades still, 6.3 million children and young adolescents died in 2017. And the most shocking aspect of this figure was that the majority of death was due to that causes that can be preventable and treatable (1).

Children's health of a country is considered as the key indicator of its economy and quality of life. Pakistan is ranked sixth in the most populous country in the world (2). Pakistan faces high pressure towards its commitment to the millennium developmental goal of which four goals are directly related to improvement in children's health. Despite all efforts of the government still newborn, infant and under-five mortality rate is very high in Pakistan. Health inequalities and disparities are common both in urban and rural areas and between provinces. There is a high infant mortality rate in rural areas as compared to urban areas. The number of underfive mortality rates is higher in Baluchistan which is 111 as compared to Khyber Pakhtunkhwa in which it is 70 . In Pakistan, $21 \%$ of the population live below the level of poverty and lacking access to basic facilities of living (3). It is estimated that one child out of every 11 died before reaching age 5. Major causes of under-five deaths are birth asphyxia leading to $22 \%$ deaths, sepsis leading to $14 \%$, Pneumonia leading to $13 \%$, diarrhea $11 \%$, and prematurity $9 \%$. Which demand a high focus on the problem and need of interventions to improve the status of health in the country(4).

Pakistan has failed to achieve the millennium developmental goal due to poor immunization status of children and a high under-five mortality rate which is reported as 75/1000 live births. Despite all efforts of the government on maternal and child health policies still, the newborn mortality rate is very high and reported as 44/1000 live births and the infant mortality rate is 61/1000 live births (5). Due to lack of facilities for antenatal care or lack of accessibility $16 \%$ of babies born are preterm and $32 \%$ are underweight. That is a major cause of infant morbidity and mortality (6). A report on the status of children in Pakistan showed that the majority of children are malnourished in which $45 \%$ of children showed evidence of chronic malnutrition and $11 \%$ showed signs of acute malnutrition(7). 


\section{Determinants of child health}

Child health is multifactorial, a number of factors affecting child health including prenatal, postnatal care, parenting style, parents education, social environment, physical environment, poverty, housing, availability and accessibility of health services. All these factors are surrounding around five major domains child, parents or family, parenting, social support services, and effective community involvement (8).

\subsection{Prenatal and postnatal care}

Children's health is greatly influenced by prenatal and postnatal care. A number of congenital defects occur during the early period of organogenesis in the womb. Factors including diet, radiations, smoke, medicines, and infections influence the child's normal growth and development in the womb. So periodic prenatal visits and avoidance of such toxins are important for proper growth and development. The postnatal environment also has a great influence on the provision of adequate care, attachment, warmth, and early fulfilling the child's needs and demands. Research showed that early and strong mother-child attachment has a great effect on the healthy growth and development of children. Many nutritional problems such as malnutrition have sometimes rooted in Psychological Issues.

\subsection{Social determinant:}

Social determinants have a great role in children's health various social determinants such as income, education, health behaviors are widely contributed to children's health. These social determinants are widely under the control of many social and political factors and beyond the approach of parents (9).

\subsection{Social norms and values}

Social norms and values are affecting child-rearing practices. There is gender bias or gender inequality in boys and girls that leading towards fewer opportunities for diet, and education for girls as compared to boys. Further breastfeeding practices are also preferred in some cultures and in other, it is a sign of stigma especially in public places. Some food preferences also influenced some cultures affecting child health.

\subsection{Socioeconomic status}

There is a higher rate of infant and child mortality and morbidity in poor families. In lower socio-economic class children suffer malnutrition and poor access to health care facilities. There is also an increased rate of low weight and preterm births in poor families. It is also reported that children with low socioeconomic status have more mental health problems as compared to children with higher socioeconomic status. Children in poor families have fewer opportunities for education and cognitive development and more at risk of physical, emotional and sexual abuse (10).

\subsection{Education}

There is a significant relationship between the level of education and the incidence of mental health problems. It is found that there is a higher incidence of mental health problems in children having parents with a low level of education (11). Further research showed that maternal education is very important for healthy growth and development of children as educated mothers have more knowledge regarding a balanced diet, hygiene and childcare so improved children's health and development.

\subsection{Parenting style}

Parenting beliefs, attitudes, values and styles also influenced children's adequate growth and development and influenced many psychological and social problems in children. Parents who are responsive towards their children need having strong bonding with their children. Parents effect directly through their caring attitude giving them a sense of security and influence their healthy physical mental and social development. On the other hand, the strict, abusive and inconsistent parenting leads towards weak parent-child attachment and further leads to antisocial response in children and mental or psychological issues.

\subsection{Personal hygiene and parents health practices}

Parents who are aware of the importance of personal hygiene such as washing hands after toileting and before eating also have a great impact on their children's health. Parent's knowledge about healthy health habits such as the use of iodized salt, exercise, and benefits of a balanced diet having children with adequate growth and development. Knowledge about preventive measures of disease such as flu, HIV, and hepatitis has greatly influenced their children's health and development (12). Further research showed that parent's education and knowledge regarding unintentional injuries also have a significant impact on the prevention of injuries underfive children (13). 


\subsection{Housing}

Housing and adequate living conditions also influenced children's health. Children live in slums with poor housing conditions suffered more illnesses such as diarrhea and respiratory infections having a higher rate of mortality and morbidity. Housing has a great impact on child physical, social and mental development. Accidents are more common among homeless children. Congested homes with poor ventilation are associated with mental health illness in children.

\subsection{Environment}

Environment concerned with the physical conditions in which children live. Children who have access to parks playland and green areas are more developed as compared to those who lack such facilities and live in congested areas having no adequate facility for play and recreation. Such children have been found more mental disorders and less coping skills in different kinds of situations. Further the quality of air, pollution, and smoke also badly affects children's health. Children living in factory areas having more respiratory tract infections, skin, eye infections and hearing problems due to smoke, and noise pollution (14).

\subsection{Availability and accessibility of Health care services}

The availability and accessibility of health services are also a strong determinant of children's health in Pakistan. As there are a lot of people living in poverty and a large number of people living in rural areas. They don't have such resources to timely access to health services. Inadequate knowledge regarding disease and its prevention their children are more prone to health problems. Pakistan is among those countries in which there is a great deal of health inequalities. A large number of people don't have any access to such a facility. People living in disadvantaged areas or those having children with disabilities suffered badly.

\section{Collaborative role of Parents, community and health care system in child health}

Child health is broadly under the influence of parents, community, and health services. So there is a need to develop a plan of action that addresses all these factors and bring their collaborative approach necessary for elevating child health status. The Better Start Child Health and Development Research Group at the University of Adelaide's School of Population Health give a rubric of "Five by Five" that is based on the concept that there are five basic domains of development and depends on five stages that require coordination of parents, families, communities, health services, and private organization. Five by five address child health at five steps 1 . Child rights to health, 2. Parenting, 3. Supporting parents and carers, 4. Supporting social systems (health services, school, childcare centers, child protection centers, Non-government organizations) 5. Supporting Communities (15).

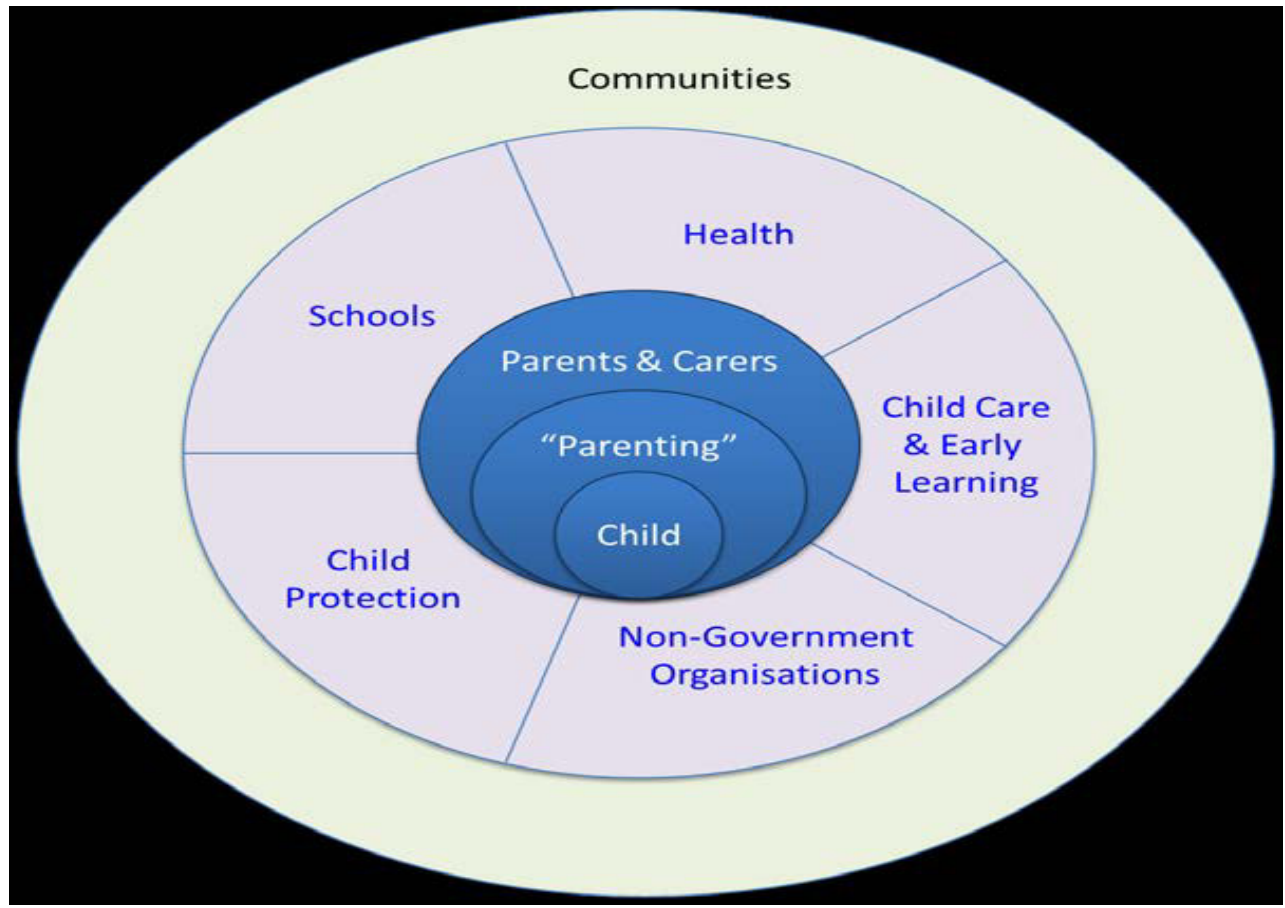

Figure: A child-centered approach for social system support of the Five by Five. Adapted from the UCL Institute of Health Equity report “An Equal Start: improving outcomes in Children's Centers” (15) . 


\subsection{Child right to health}

The first focus should be on the child and its basic right to health. There are multiple factors including parents, their skill of parenting, availability of resources including supportive community, provision of health services, the important role of non-government organizations are all important in improving the health status of children in Pakistan.

\subsection{Parenting}

Parenting plays an important role in child health. Parent's attitude towards their children is highly affected by child physical, mental and social development. So identifying those factors that hinder effective parenting are important and provision of support knowledge and education regarding child-rearing practices will positively affect child health. Parent's knowledge about child early growth and development and its deviations will lead to an early approach to health care services that lead to a better outcome (16).

\subsection{Supporting Parents \& Carers}

Parents and carer support is also very important as it is evidenced by research that parent socioeconomic status, income, mental disorders, history of abuse, and lack of resources to provide basic facilities of life has a great impact on children's health. It is evident that children who lived with parents having better income and jobs are more physically and mentally develop as compared to those children living with unemployed parents. So identifying such parents and support through different programs to meet the basic needs of their children and providing employment opportunities will bring a better outcome on child health (17).

\subsection{Supporting Social Systems (health services, schools, childcare, child protection, \& nongovernment organizations)}

Supporting and coordinating efforts of all five systems related to child health including health services, schools, childcare, and early learning, child protection, and non-government organizations will affect child health and development. Health services should improve their services and involve parents and families in health education and education regarding the early signs of deviations from normal growth and development. Effective services should be provided and education regarding children's nutritional demands, hygiene, exercise, psychological demands of children and effective parenting skills should be taught to prevent disease and promote health. Schools, childcare centers, child protection centers and non-government organizations play an important role in identifying and reducing those factors that affect child health (18).

\subsection{Supporting Communities}

Child health and development is widely depending on community support. In community social norms, values, social infrastructure, information sharing, social support and connectedness, sharing and allocation of resources, supportive and protective environment for early learning and a commitment towards excellence all effecting on child health. So community engagement and coordination with health services, non-government organizations are playing an important role in child health and development (19).

\section{Call to Action}

The important role of parents, community and health care system in raising the status of children's health and closing gaps could not be denied. An effective plan of action and policies must be made and implemented that assist and encourage parents, families, and communities to work in collaboration with health care services and become an integral part of improvement efforts. There should be joint efforts in early recognition of disease, referral, and immunization for every child. If we want to enter a new era of national development we feel the responsibility towards children and improve their health up to the mark of international standards.

\section{Funding statement}

No funding is received and provided for writing this article.

\section{References}

1. Who, UNICEF, and World Bank Group. (2018). Nurturing care for early childhood development: a framework for helping children survives and thrives to transform health and human potential. Geneva: WHO; [internet]. Available https://apps.who.int/iris/bitstream/handle/10665/272603/9789241514064eng.pdf.(September 22, 2019).

2. The world population and the top ten countries with the highest population (2018). Internet world statistics. [internet] Available: https://www.internetworldstats.com/stats8.htm. (September 22, 2019).

3. Cesare, M.D., Bhatti, Z., Soofi, S. B., Fortunato, L., Ezzati, M., Bhutta, Z. A. (2015). Geographical and socioeconomic inequalities in women and children's nutritional status in Pakistan in 2011: an analysis of 
data from a nationally representative survey. Lancet, 3(4), 229-239.

4. Shoukat, M., Khurml, M. S., \& Faheem, M. U. (2015). Child health status in Pakistan. JAMC, $1,1$.

5. UNICEF. (2018). Data monitoring the situation of children and women in Pakistan. [internet] Available : https://data.unicef.org/country/pak/. (September 24, 2019).

6. UNICEF. (2018). Pakistan. Scale-up of Kangaroo Mother Care Services in Pakistan. UNICEF Pakistan. [internet] Available https://www.unicef.org/pakistan/media_10608.html. (September 22, 2019).

7. UNICEF. (2015). The state of children in Pakistan. [internet] Available: www.unicef.org/pakistan. (September 24, 2019).

8. Robinson, L. R., Holbrook, J. R., Bitsko, R. H., Hartwig, S. A., Kaminski, J. W., Ghandour, R. M. et al. (2017). Differences in Health Care, Family, and Community Factors Associated with Mental, Behavioral, and Developmental Disorders Among Children Aged 2-8 Years in Rural and Urban Areas - United States, 2011-2012. Morbidity and mortality weekly report. Surveillance summaries, 66(8), 1-11.

9. Spencer, N. (2018). The social determinants of child health. Pediatric and child health, 28(3), 138-143

10. AAP Council on community pediatrics. (2016). Poverty and Child Health in the United States. Pediatrics, $137(4)$.

11. Leslie, G., Heather, J., S. I. (2015). Children of the new century: mental health findings from the Millennium Cohort Study. [internet] Available https://www.researchgate.net/publication/308083993_Children_of_the_new_century_ mental_health_findings_from_the_Millennium_Cohort_Study. (Aügust 12, 2019).

12. Afzal, U. (2012). The Determinants of Child Health and Nutritional Status in Punjab: An Economic Analysis. 2012. [internet] Available http://www.creb.org.pk/uploads/Working-Paper-No.-02-12-FinalComplete.pdf. (July 12, 2019).

13. Nauman, Y., Hussain, M., Afzal, M., \& Gilani, S. (2019). Effectiveness of health education among mothers to reduce unintentional home injuries of fewer than five-year-old children in a rural community. Pakistan journal of public health, 26-29.

14. WHO and UNICEF. (2019). Nurturing care for early childhood development - A global framework for action and results. [internet] Available https://www.who.int/maternal_child_adolescent/child/nurturing-careframework-first-draft.pdf. ( September 24, 2019).

15. Sawyer, A. 1., Gialamas, A. A. 1., Pearce, A., Sawyer, M. G., \& Lynch, J. 1., (2014). Five by Five: A Supporting Systems Framework for Child Health and Development. School of Population Health, University of Adelaide.

16. Benveniste, J. A. (2013). Practice guide for working with families from pre-birth to eight years: engaging families in the early childhood development story. Victoria, Australia.

17. Jorm, A. F. (2012). Mental health literacy: empowering the community to take action for better mental health. American Psychologist, 67(3), 231

18. Health Minister's Advisory Council. (2011). National Framework for Universal Child and Family Health Services: Vision, objectives, and principles for universal child and family health services for all Australian children aged zero to eight years: Australian Government Department of Health and Ageing.

19. McLachlan, R., Gilfillan, G., \& Gordon, J. (2013). Deep and Persistent Disadvantage in Australia. Melbourne: Australian Government Productivity Commission. 